\title{
Mortality in acute upper gastrointestinal haemorrhage: a six-year survey from the University Hospital of Wales
}

\author{
J. F. MAYBERRY \\ B.Sc., M.D., M.R.C.P. \\ B. R. COUNSELL \\ M.B.
}

\begin{abstract}
Summary
In a retrospective survey of normal hospital practice, 583 patients were admitted between March 1972 and 1978 because of haematemesis or melaena. Sixty $(10 \cdot 3 \%)$ of these patients died; most deaths occurred in elderly patients (mean age 75 years) $75 \%$ of whom had a serious medical problem which complicated the situation. Malignancy, cardiovascular disease and respiratory problems were the most commonly associated factors. The attitude towards both emergency investigation and surgical intervention was very conservative and any reduction in mortality would require a concerted effort to deal with the special problems in elderly patients who are at particular risk.
\end{abstract}

\section{Introduction}

Gastrointestinal haemorrhage accounts for approximately 25000 admissions to hospital each year with an overall mortality of $9 \%$; based on these figures, more than 2000 deaths are associated with haemorrhage each year in England and Wales (Schiller, Truelove and Williams, 1970). There has been a fall in the number of hospital admissions for peptic ulcer in recent years (Brown, Langman and Lambert, 1976), so that this figure may be an over-estimate. The authors examined the source of haemorrhage and cause of mortality in a group of 583 patients admitted to the University Hospital of Wales between 1972 and 1978. Sixty patients died, giving a mortality of $10.3 \%$. The events which preceded death were examined in detail to identify contributory factors.

\section{Method}

Patients admitted to the University Hospital of Wales with a diagnosis of haematemesis or melaena were all recorded in the admission unit which made it possible to identify the total group of 583 patients in the 6-year period. The notes of 565 of these patients were subsequently retrieved from the Medical Records Department and the following details were taken from their notes.

The site of haemorrhage was recorded if this was known and also whether the diagnosis had been established by barium meal, endoscopy, surgery or a combination of these. The pulse rate and BP on admission were noted, in addition to the $\mathrm{Hb}$ and blood urea. A note was made of whether the patients were given a transfusion and an attempt was made to record the quantity of blood given but the latter was sometimes poorly documented. Other clinical details included patient's age, sex, smoking and drinking habits and any recent history of aspirin or other analgesic consumption before admission. Additional information was collected about 84 of the patients who underwent surgery and from all of those who died.

\section{Results}

The analysis was based on 565 patients whose notes were examined. Fifty-seven of these died during the hospital admission. Of the 18 cases whose notes were not retrieved, 3 died.

Some personal details of patients are in Table 1 where the survivors are compared with the group who died. The mean age of the group who died was almost 20 years greater than for those who survived ( 75.4 years compared with 57.9 years), and relatively more men than women died, with a ratio of 1.9:1 compared with 1.6:1 for those who survived. The age distributions of patients who survived and those who died are in Fig. 1. Only 5 patients died under 60 years of age while 21 of the deaths were in patients over 80 years of age. In Fig. 2 the percentage mortality for different age groups of the patients admitted with a gastrointestinal haemorrhage is compared with the National Mortality figures for England and Wales for 1973 (Registrar General, 
1974). Gastrointestinal haemorrhage increased the risk of death at all ages, particularly over 70 years of age and the increase in mortality was 2 to 3 times.

TABLE 1. Personal characteristics and management of patients with an upper gastrointestinal haemorrhage admitted to the University Hospital of Wales between 1972-1978

\begin{tabular}{|c|c|c|c|c|}
\hline \multicolumn{5}{|c|}{$\begin{array}{l}\text { Patient characteristics and management } \\
\qquad \begin{array}{c}\text { Patients } \\
\text { surviving } \\
(n=508)\end{array}\end{array}$} \\
\hline $\begin{array}{l}\text { Mean age } \\
\text { Range } \\
\text { Sex ratio (male:female) }\end{array}$ & \multicolumn{2}{|c|}{$\begin{array}{l}57 \cdot 9( \pm 31 \cdot 1) \\
3-95 \\
1 \cdot 6: 1\end{array}$} & \multicolumn{2}{|c|}{$\begin{array}{l}75 \cdot 4( \pm 11 \cdot 5) \\
42-94 \\
1 \cdot 9: 1\end{array}$} \\
\hline $\begin{array}{l}\text { Smoker } \\
\text { Drinker } \\
\text { Aspirin taken recently } \\
\text { Other analgesic taken } \\
\quad \text { recently }\end{array}$ & $\begin{array}{l}234 \\
258 \\
109\end{array}$ & $\begin{array}{l}(46 \%) \\
(41 \%) \\
(22 \%)\end{array}$ & $\begin{array}{r}9 \\
20 \\
8\end{array}$ & $\begin{array}{l}(16 \%) \\
(35 \%) \\
(14 \%)\end{array}$ \\
\hline No radiology or endoscopy & 81 & $(16 \%)$ & 28 & $(50 \%)$ \\
\hline $\begin{array}{l}\text { Site of haemorrhage not } \\
\text { defined }\end{array}$ & 167 & $(33 \%)$ & 17 & $(30 \%)$ \\
\hline Surgery & 73 & $(14 \%)$ & 11 & $(19 \%)$ \\
\hline Post-mortem & & - & 20 & $(35 \%)$ \\
\hline
\end{tabular}

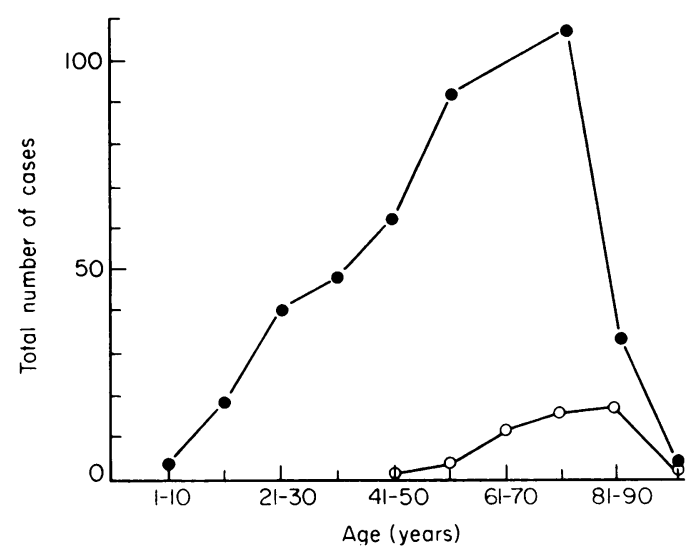

FIG. 1. Age distribution of patients admitted to the University Hospital of Wales between 1972 and 1978 with haematemesis and melaena.

$\longrightarrow$, patients who survived $(n=508)$;

$\bigcirc-\bigcirc$, patients who died $(n=57)$.

\section{Emergency investigations}

Blood pressure, pulse, the initial $\mathrm{Hb}$ and blood urea concentrations were of little value in identifying patients at risk. The figures for each of these values were remarkably similar in the groups who survived and those who eventually died (Table 2). Four hundred and seventy-six patients were investigated to determine the source of bleeding (Table 3); 264 of these by barium meal alone, 56 by endoscopy alone, and in 136 both procedures were used. On hundred and nine patients were not investigated an\& 28 of these died during their hospital admission:

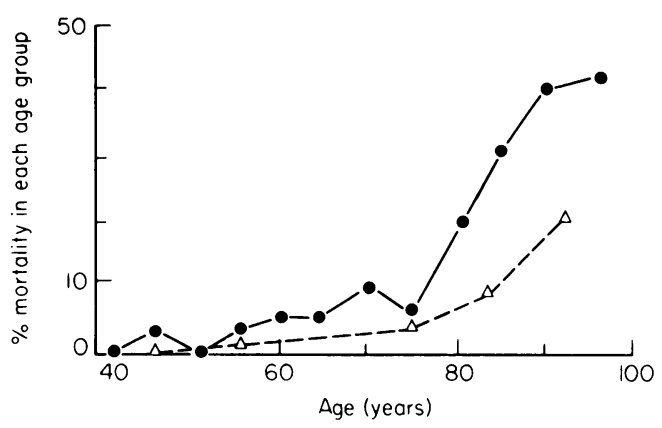

FIG. 2. Mortality from haematemesis and melaena is ex pressed as a percentage for different age groups $-\longrightarrow$ and compared with the total mortality in each age group through out England and Wales in 1973 (Registrar General, 1979 $\triangle \cdots \Delta$.

TABLE 2. Initial investigations on patients admitted University Hospital of Wales with an upper gastrointestin(1) haemorrhage between 1972 and 1978. Means ( \pm s.d.) ae recorded

\begin{tabular}{|c|c|c|c|}
\hline $\begin{array}{l}\text { Initial } \\
\text { investigations } \\
\text { Blood pressure: }\end{array}$ & \multicolumn{2}{|c|}{$\begin{array}{l}\text { investigations } \\
\text { Patients surviving } \\
\quad(n=508)\end{array}$} & $\begin{array}{l}\text { Dea里sce } \\
(n=3)\end{array}$ \\
\hline $\begin{array}{l}\text { Blood pressure: } \\
\text { Systolic }(\mathrm{mmHg}) \\
\text { Diastolic }(\mathrm{mmHg})\end{array}$ & $\begin{array}{r}130 \\
78\end{array}$ & $\begin{array}{l}(25) \\
(16)\end{array}$ & $\begin{array}{r}119 \\
68\end{array}$ \\
\hline Pulse (rate/min) & 94 & (18) & $94 \quad(19$ \\
\hline Haemoglobin $(\mathrm{g} / \mathrm{dl})$ & $11 \cdot 7$ & $(3 \cdot 2)$ & $10.8(3$. \\
\hline Urea (mmol/l) & 24 & (25) & 18 \\
\hline
\end{tabular}

TABLE 3. Investigation of patients admitted to the Universi Hospital of Wales with an upper gastrointestinal haemovrhage between 1972 and 1978

\begin{tabular}{|c|c|c|}
\hline \multicolumn{3}{|c|}{$\begin{array}{c}\text { Emergency investigation of upper gastrointestinal } \\
\text { haemorrhage }\end{array}$} \\
\hline Investigation & $\begin{array}{l}\text { Patients surviving } \\
\quad(n=508)\end{array}$ & $\begin{array}{l}\text { Deaths } \\
(n=57)\end{array}$ \\
\hline Endoscopy alone & 46 & 10 \\
\hline Barium meal alone & 253 & 11 \\
\hline Both examinations & 128 & 8 \\
\hline Neither examination & 81 & 28 \\
\hline
\end{tabular}

Failure to investigate some patients may warranted in those with small haemorrhages bof this is scarcely applicable to those who died. Of the $28(49 \%)$ patients who died who were not invest gated 5 had prior evidence of malignancy. A failure to investigate may reflect their age which led to $\frac{9}{2}$ more conservative approach but only 5 others wege later found to have a carcinoma at post-mortem examination. 


\section{Site of haemorrhage}

The site of bleeding was identified in only 381 patients (Table 4). In 184 patients the source of haemorrhage was not identified but most of these had a small haemorrhage which was not investigated. However, no source of bleeding was identified in 17 patients who died and these were chiefly elderly.

TABLE 4. Major sites of upper gastrointestinal haemorrhage presenting at the University Hospital of Wales between 1972 and 1978. Sixteen of the patients with an unusual cause of bleeding had anastomotic ulcers or bled from multiple sites. Three of these patients died and are included with peptic ulceration in other tables. A further patient who died bled from both varices and a gastric ulcer and is not included in either group in the other tables

\begin{tabular}{|c|c|c|}
\hline Sites of gastroin & $\begin{array}{l}\text { testinal haemorrhage } \\
\text { Patients surviving } \\
\qquad(n=508)\end{array}$ & $\begin{array}{l}\text { Deaths } \\
(n=57)\end{array}$ \\
\hline \multicolumn{3}{|l|}{ Oesophagus } \\
\hline Varices & 11 & 8 \\
\hline Erosions & 12 & 1 \\
\hline Ulcer & 5 & 0 \\
\hline Carcinoma & 0 & 2 \\
\hline Mallory-Weiss syndrome & 6 & 0 \\
\hline \multicolumn{3}{|l|}{ Stomach } \\
\hline Ulcer & 93 & 5 \\
\hline Erosions & 13 & 1 \\
\hline Carcinoma & 28 & 6 \\
\hline \multicolumn{3}{|l|}{ Duodenum } \\
\hline Ulcer & 146 & 8 \\
\hline Undefined & 167 & 17 \\
\hline Unusual causes & 27 & 9 \\
\hline
\end{tabular}

The major sources of haemorrhage included duodenal ulcer in 154 patients, gastric ulcer in 98 , carcinoma of the stomach in 34 , and oesophageal varices in 19. The age distribution for 3 of these

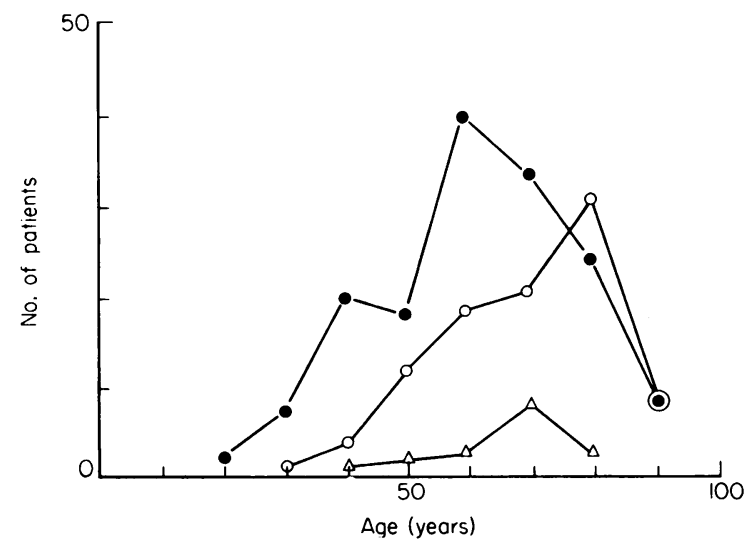

FIG. 3. Age distribution of patients presenting with haemorrhage from duodenal ulcer $(\bullet-\bullet)$, gastric ulcer $(O-O)$ and oesophageal varices $(\triangle-\Delta)$. All the patients were admitted to the University Hospital of Wales between 1972 and 1978. groups (Fig. 3) shows a peak value for duodenal ulcer about 60 years of age, for oesophageal varices about 70 and for gastric ulcer about 80 years. Other less common causes in the series included 2 patients with the Zollinger-Ellison syndrome, one with Henoch-Schönlein purpura, one with hereditary telangiectasia, another with an antral haemangioma, 2 with a gastric volvulus and one with Hodgkin's disease of the stomach. Unusual causes of haemorrhage from the intestine included one patient with ectopic pancreatic tissue, 2 with carcinoma of the pancreas invading the duodenum and one with carcinoma of the gall-bladder involving the duodenum. One patient bled from a duodenal leiomyoma, another from a Meckel's diverticulum and a third from intestinal infarction. Post-mortem examinations were performed in only 20 of the 57 patients who died, which limits the knowledge of the precise cause of death.

\section{Management}

Fifty-one per cent. of patients who survived an upper gastrointestinal haemorrhage required transfusion and an average of 2.9 units was used. Blood was given more often and in greater quantities to patients who eventually died, which probably reflects severe and more prolonged haemorrhage because the initial $\mathrm{Hb}, \mathrm{BP}$ and pulse measurements were all similar.

\section{Surgery}

Eighty-four (15\%) of the 565 patients underwent surgery and 11 of these died. Death occurred on an average 12 days after the procedure and was associated with postoperative pneumonia in 5 . Four of them had a gastric ulcer which was treated by Bilroth I partial gastrectomy in 3 and a partial gastrectomy with gastro-enterostomy in one. Three of the patients had a duodenal ulcer treated by a polya-gastrectomy in 2 and a vagotomy and pyloroplasty in one patient. Of the remaining 4 patients, one had a Milnes-Walker procedure for bleeding oesophageal varices, one excision of ectopic pancreatic tissue and 2 had inoperable gastric carcinoma.

There were 4 major groups who died-patients with malignant disease, peptic ulcer, oesophageal varices and those in whom the site was not identified. It is difficult to define the precise cause of death in these 57 patients; in most of them there was a major contributory factor (Fig. 4). Fifteen patients had serious cardiovascular disease, 8 of them were in congestive cardiac failure, 3 had pulmonary emboli, 2 had a myocardial infarction with cardiac arrest and a further 2 had severe hypertension. Six other patients had either severe respiratory disease or developed a lobar pneumonia. Eighteen patients 
had malignant disease and in 7 of these the malignancy was in the stomach or oesophagus; other sites included the bronchus, pancreas and gall-bladder. Eight patients died from bleeding oesophageal varices which complicated chronic liver disease. A further 9 patients with other miscellaneous problems could not easily be classified as a single group.

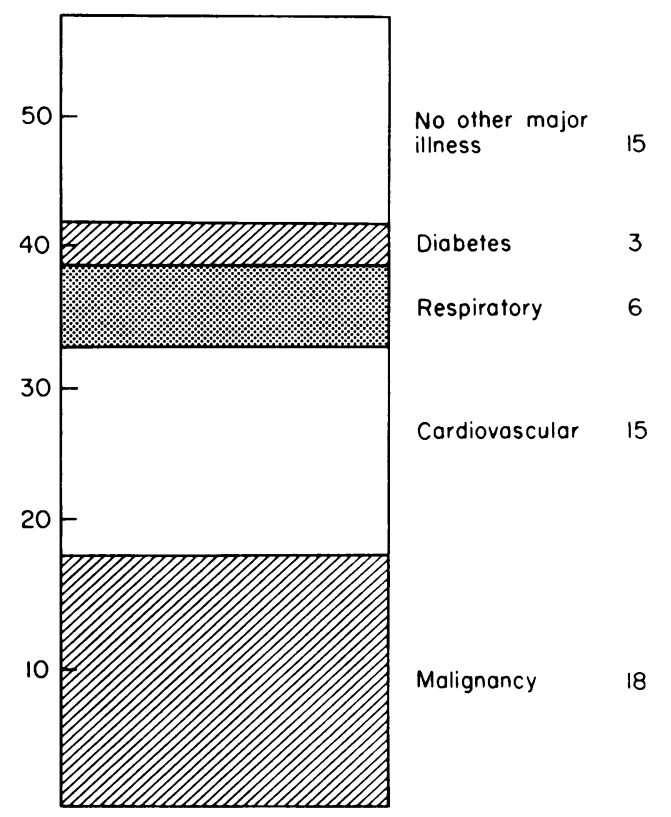

FIG. 4. Contributory problems in 57 patients who died from a haematemesis and melaena at the University Hospital of Wales between 1972 and 1978.

\section{Peptic ulcer}

Eighteen of the patients with a peptic ulcer died and their mean age was 80 years (Table 5). Most of them (16 patients) required a large transfusion (mean 7.7 units) and died some time after admission (mean 11 days). Only 7 of them underwent surgery

\section{Oesophageal varices}

The mean age of those patients who died wi oesophageal varices was 63 years (Table 5). The received an average transfusion of 13 units.

In the 17 patients who died without identification of the site of haemorrhage, the mean age was 80 years but the transfusions given were relative small (mean 2.9 units).

\section{Discussion}

Overall mortality in the group of 583 patients was about $10 \%$ which is similar to other series in the current literature (Schiller et al., 1970; Johnstor et al., 1973). This figure has remained remarkabfy consistent over the past 20 years; advances \& clinical management, surgical and anaesthetic skins have probably been counterbalanced by an increasing number of elderly patients in the groups during this time (Allan and Dykes, 1976).

Factors which appeared to determine the eventuat outcome were age and the presence of a seriogs contributory medical condition as previously shown by Morgan et al. (1977). Almost all the degthas occurred in patients over the age of 60 years ang $36 \%$ of them were in patients over the age of years. It is hard to escape the conclusion that the attitude towards vigorous resuscitation is probably different for elderly patients who have other chrond diseases. In such circumstances, those involved the management are probably unwilling to treat the patient surgically. The largest group of deaths we $\overrightarrow{\bar{c}}$ those patients in whom the cause of haemorrhage was not identified (17) and the authors were somet what surprised to find that $49 \%$ of the patients who died had not been investigated by either bariug

TABLE 5. Features of patients who died with a haematemesis from a peptic ulcer, varices or in whom the site was not defined. Mean ( \pm s.d.) is given

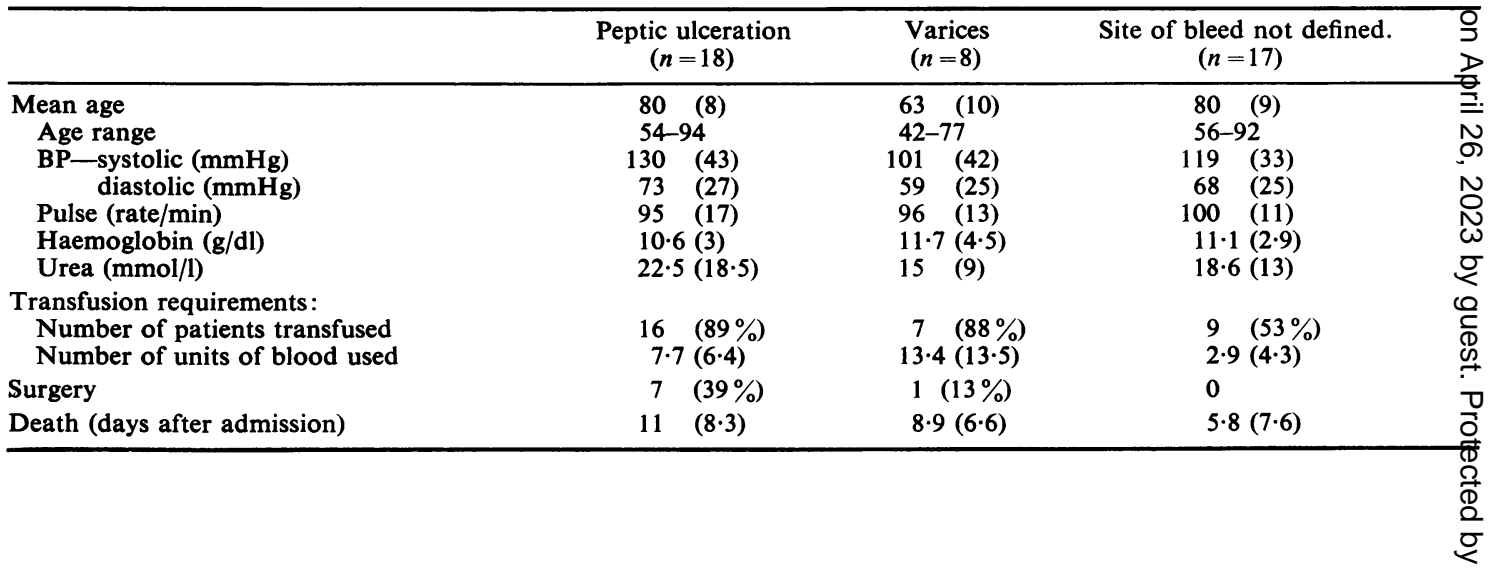


meal or endoscopy, and they cannot justify this policy. The other substantial groups where death occurred include duodenal ulcer (8), oesophageal varices (8), gastric and oesophageal carcinoma (8), and gastric ulcer (5).

In the group of survivors more patients were smokers, regularly drank alcohol or took analgesics. These findings probably reflect the high incidence of acute erosions in the group. Only 191 of 476 patients had had an endoscopy, despite its availability. Although it is the most accurate method for diagnosis in acute upper gastrointestinal haemorrhage, increased diagnostic accuracy has not been shown to improve the ultimate prognosis (Logan and Finlayson, 1976).

This series reflects a conservative surgical approach where only 84 of 565 patients $(15 \%)$ had an operation. The operative rate in other series varies from 20 to $35 \%$ (Schiller et al., 1970; Allan and Dykes, 1976; Cotton et al., 1973). Since many deaths occurred after a prolonged stay in hospital (mean stay 11 days for the peptic ulcer group) and a large transfusion (mean 7.7 units in peptic ulcer group), one could propose that a more aggressive surgical approach should be considered in elderly patients with continued or recurrent haemorrhage, particularly in the absence of any other serious illness. However, one must concede that the overall mortality was in the expected range in spite of the low operative rate. A minimal surgical procedure which is adequate to stop haemorrhage should be used (Dronfield and Langman, 1978). In one series, mortality in duodenal ulcer after an emergency vagotomy and pyloroplasty was only $5.5 \%$ compared with about $15 \%$ after gastrectomy (Clark, 1968).

Early surgical management for elderly patients in this situation has previously been advocated (Jones et al., 1973) but there is reluctance to embark on this policy because the elderly tolerate surgery poorly (Allan and Dykes, 1976; Logan and Finlayson, 1976). In several series, $33 \%$ of deaths can be related to surgery (Schiller et al., 1970; Allan and Dykes, 1976; Logan and Finlayson, 1976) and mainly associated with postoperative complications. Careful management of the elderly may well reduce mortality. Precisely how this is organized would vary with different hospital situations, but there is probably a place for an intensive care facility to deal with the problem in many cases (Allan and Dykes, 1976; Venables, 1980). It is certainly true that where special attention is given to the clinical problem mortality appears to fall substantially (Jones, 1947) and this may simply reflect better overall care rather than the introduction of any special procedure. A recent prospective study from Australia by Hunt, Hansky and Korman (1979) of 817 patients over a 6-year period showed a significant fall in mortality from $9 \%$ to $2.4 \%$. Although the operative rate remained the same, operative mortality fell from $16 \%$ to $1.6 \%$ and the prognosis for patients with a bleeding gastric ulcer improved most.

Since emergency surgery contributes to the high mortality (Allan and Dykes, 1976), minimal procedures for effecting haemostasis are desirable. Endoscopic sclerotherapy is of value for bleeding varices and is associated with considerably reduced mortality compared with transthoracic ligation of varices (Johnston and Rodgers, 1973). Endoscopic electro-coagulation may be used to treat nonvariceal bleeding which does not respond to conventional treatment, but results are often temporary and further definitive treatment is usually required (Papp, 1976). Endoscopic laser photo-coagulation remains to be assessed fully but it is potentially a therapeutic advance but we must await results from controlled clinical trials and a reduction in its unit cost before it can be recommended widely (Protell, Silverstein and Auth, 1978).

Retrospective studies are limited by incomplete data but they reflect actual rather than ideal practice. Undoubtedly, prospective trials affect the management of patients and probably lead to a more accurate diagnosis, vigorous resuscitation and in some cases earlier surgical intervention which may reduce mortality. One is left with the unresolved dilemma of whether and when patients should go to surgery in the absence of controlled trials to support a particular policy which would consistently reduce mortality.

\section{Acknowledgments}

We gratefully acknowledge help from Mrs B. Pelling and Miss Margaret Meek in retrieving notes and to the Department of Medical Photography for illustrations.

\section{References}

Allan, R. \& Dykes, P. (1976) A study of the factors influencing mortality rates from gastrointestinal haemorrhage. Quarterly Journal of Medicine, 45, 533.

Brown, R.C., LANGMaN, M.J.S. \& LAMBert, P.M. (1976) Hospital admissions for peptic ulcer during 1958-72. British Medical Journal, 1, 35.

Clark, C.G. (1968) Surgical aspects of gastro-intestinal haemorrhage. Postgraduate Medical Journal, 44, 590.

Cotton, P.B., Rosenberg, M.T., Waldram, R.P.L. \& Axon, A.T.R. (1973) Early endoscopy of oesophagus, stomach and duodenal bulb in patients with haematemesis and melaena. British Medical Journal, 2, 505.

Dronfield, M.W. \& LANGMan, M.J.S. (1978) Acute upper gastro-intestinal bleeding. British Journal of Hospital Medicine, 19, 97.

Hunt, P.S., Hansky, J. \& Korman, M.G. (1979) Mortality in patients with haematemesis and melaena; a prospective study. British Medical Journal, 1, 1238.

Johnston, G.W. \& RoDGERs, H.W. (1973) A review of 15 years' experience in the use of sclerotherapy in the control of acute haemorrhage from oesophageal varices. British Journal of Surgery, 60, 797. 
Johnston, S.J., Jones, P.F., Kyle, J. \& Needham, C.D. (1973) Epidemiology and course of gastrointestinal haemorrhage in North-east Scotland. British Medical Journal, 3, 655 .

JoNES, F.A. (1947) Haematemesis and melaena with special reference to bleeding peptic ulcer. British Medical Journal, 2,441 .

Jones, P.F., Johnston, S.J., McEwan, A.B., Kyle, J. \& NeEdHAM, C.D. (1973) Further haemorrhage after admission to hospital for gastro-intestinal haemorrhage. British Medical Journal, 3, 660.

Logan, R.F.A. \& Finlayson, N.D.C. (1976) Deaths in acute upper gastrointestinal bleeding: can endoscopy reduce mortality? Lancet, $\mathrm{i}, 1173$.

Morgan, A.G., McAdam, W.A.F., Walmsley, G.L., Jessop, A., Horrocks, J.C. \& DE Dombal, F.T. (1977) Clinical findings, early endoscopy, and multivariate analysis in patients bleeding from the upper gastro
intestinal tract. British Medical Journal, 2, 237.

PAPP, J.P. (1976) Endoscopic electrocoagulation of upper. gastrointestinal haemorrhage. Journal of the America Medical Association, 236, 2076.

Protell, R.L., Silverstein, F.E. \& Auth, D.C. (1978 Laser photocoagulation for gastro-intestinal bleeding Clinics in Gastroenterology, 7, 765.

RegistraR GeNERAL (1974) National mortality figures fơ 1973. In: Statistical Review of England and Wales, 197g H.M. Stationery Office, London.

Schiller, K.F.R., Truelove, S.C. \& Williams, D.C (1970) Haematemesis and melaena with special reference to factors influencing outcome. British Medical Journa?, $2,7$.

Venables, C.W. (1980) Advances in the management of gastrointestinal bleeding. British Journal of Hospito Medicine, 23, 338. 